\title{
Effects of air pollution exposure on social behavior: a synthesis and call for research
}

\author{
Chelsea A. Weitekamp ${ }^{1 *}$ and Hans A. Hofmann ${ }^{2,3,4}$
}

\begin{abstract}
Background: There is a growing literature from both epidemiologic and experimental animal studies suggesting that exposure to air pollution can lead to neurodevelopmental and neuropsychiatric disorders. Here, we suggest that effects of air pollutant exposure on the brain may be even broader, with the potential to affect social decision-making in general.
\end{abstract}

Methods: We discuss how the neurobiological substrates of social behavior are vulnerable to air pollution, then briefly present studies that examine the effects of air pollutant exposure on social behavior-related outcomes.

Results: Few experimental studies have investigated the effects of air pollution on social behavior and those that have focus on standard laboratory tests in rodent model systems. Nonetheless, there is sufficient evidence to support a critical need for more research.

Conclusion: For future research, we suggest a comparative approach that utilizes diverse model systems to probe the effects of air pollution on a wider range of social behaviors, brain regions, and neurochemical pathways.

Keywords: Air pollution, Social behavior, Particulate matter, Ozone, Social decision-making network, Dopamine, Sex steroids, Inhalation, Hazardous air pollutants

\section{Background}

Ambient air pollution is ubiquitous and impacts individuals across ages and all geographic regions, but also often entails inequities in exposure, thereby exacerbating socioeconomic and racial-ethnic disparities [1]. Its burden on public health is substantial, driven in part by urban development, globalized industrial production, and use of motor vehicles with internal combustion engines [2]. While it has been well-established that longterm exposure to ambient air pollution increases risk of morbidity and mortality from cardiovascular and respiratory disease [3], there is a growing literature showing that air pollutant exposure also impacts neural function and social-neurobehavioral outcomes in humans [4-6], such

*Correspondence: weitekamp.chelsea@epa.gov

${ }^{1}$ Center for Public Health and Environmental Assessment, U.S. Environmental Protection Agency, Durham, NC, USA

Full list of author information is available at the end of the article as autism spectrum disorder [7-11], bipolar disorder [12], and depression [13]. Experimental studies in animal models have supported the epidemiologic evidence, showing that in rodents, inhalation of air pollutants can lead to characteristics of neurodevelopmental and neuropsychiatric disorders [14-16]. Therefore, if exposure to air pollution can affect the incidence or severity of these disorders, even at ambient levels, how might air pollutants affect social behavior more generally? We believe this is an important question with the potential to have both societal consequences for humans and implications for wildlife. In humans, air pollution has been associated with reduced social competence (i.e., ability to effectively handle social interactions) [17] and increased violent behavior $[18,19]$, but there is a notable absence of experimental research on the effects of air pollutant exposure on social decision-making and social behavior more broadly. original author(s) and the source, provide a link to the Creative Commons licence, and indicate if changes were made. The images or other third party material in this article are included in the article's Creative Commons licence, unless indicated otherwise in a credit line to the material. If material is not included in the article's Creative Commons licence and your intended use is not permitted by statutory regulation or exceeds the permitted use, you will need to obtain permission directly from the copyright holder. To view a copy of this licence, visit http://creativecommons.org/licenses/by/4.0/. The Creative Commons Public Domain Dedication waiver (http://creativeco mmons.org/publicdomain/zero/1.0/) applies to the data made available in this article, unless otherwise stated in a credit line to the data. 
Social behavior is defined as interactions among two or more organisms where one individual affects the other, usually within the same species [20]. These behaviors can include collective behaviors such as swarming, schooling, and flocking, as well as (usually) dyadic behaviors such as parental care, pair bonding, aggressive behavior, cooperation, mate choice, and sexual behavior. Given the prominent role of hormones in mediating behavior, the effects of other environmental contaminants such as endocrine disrupting chemicals (e.g., those that interfere with hormones and their actions) have been studied in diverse taxa since the 1970s [21-23]. This research has lent insight into the dramatic ways in which chemical exposures in the environment can modify social behaviors, particularly when exposures occur during susceptible periods of development [22]. While oral and dermal sources of endocrine disrupting chemicals have been most extensively studied, another important route of exposure is through inhalation of outdoor air [24, 25]. For neural effects, inhalation is a unique route of exposure because compounds can bypass the blood-brain barrier and reach the brain directly. In the air, endocrine disrupting chemicals exist both as gases and as components of particulate matter [25]. Yet air pollution is a complex mixture and potential effects on social behavior from exposure can arise from mechanisms beyond endocrine disruption, including oxidative stress and neuroinflammation, as well as direct neuronal damage [26]. These effects can occur following exposure during development, which can lead to perturbations in brain development and subsequently alterations in adult social behavior, or from exposure in adult animals.

Air pollution is derived from both natural and anthropogenic sources. The U.S. EPA groups air pollutants into two major classes based on the way in which they are regulated: criteria air pollutants and air toxics. The six criteria air pollutants are broadly found across the U.S., have multiple sources, and may reasonably be anticipated to endanger public health or welfare. These include ozone, particulate matter, lead, nitrogen dioxide, sulfur dioxide, and carbon monoxide. The Clean Air Act of 1963 governs the establishment, review, and revision of the National Ambient Air Quality Standards for each criteria air pollutant. In 1990, amendments to the Clean Air Act identified 189 air toxics, or hazardous air pollutants, and defined a process for regulating emissions of these air pollutants. The air toxics are pollutants that cause serious irreversible, or incapacitating reversible, health effects including cancer and other serious health outcomes. There are currently 187 air toxics identified under the Clean Air Act (following delisting of two pollutants), including, for example, carbonyls, dioxins, polycyclic organic matter, polychlorinated biphenyls, and metal compounds, among many others. While levels of many air pollutants have decreased in the U.S. due to regulations under the Clean Air Act, air pollution remains a global concern. In 2016, 91\% of the world population was living in areas that exceeded the World Health Organization air quality guidelines [27].

\section{Air pollutant exposure affects the brain}

Air pollutants affect the central nervous system through both direct and indirect routes. Particulate matter is often cited as posing the greatest risk to health, which likely varies with particle size. This risk may arise from the particles themselves or from effects of the chemicals adsorbed onto the particles. Fine and ultrafine particulate matter (less than 2.5 and less than $0.1 \mu \mathrm{m}$ in diameter, respectively) can deposit into the lungs, migrate into systemic circulation, and ultimately cross the bloodbrain barrier [28-30]. Additional direct exposure routes include the potential for transport via the olfactory epithelium [31], as well as via sensory afferents in the gastrointestinal tract [4]. Once pollutants reach the brain, the innate immune system plays an important role in mediating neurotoxicity. Microglia, the resident immune cells in the brain, may attack pollutants, resulting in chronic or excessive activation and subsequent neuroinflammation through the release of pro-inflammatory cytokines and reactive oxygen species [32]. Microglia-induced neuroinflammation or oxidative stress can also occur in the absence of direct translocation to the brain [28, 33, 34]. Indeed, the dominant route of neuroimmune activation arising from air pollution exposure is likely via peripheral immune activation. For example, gaseous pollutants, such as ozone, can activate pulmonary macrophages, leading to a pro-inflammatory lung response that affects the central nervous system [34]. Therefore, air pollutant exposure can result in adverse neuronal effects via either direct or indirect contact with the brain (Fig. 1).

Notably, pollutants found in the air can also take the form of other exposure routes, such as ingestion of contaminated food or drinking water or dermal contact. For many of these pollutants, such as polychlorinated biphenyls [35], neurotoxicity and neuroendocrine disruption via oral exposure routes have been well-studied, but parallel studies that utilize inhalation exposure are lacking [36]. Inhalation of air pollutants is unique because it results in exposure to a complex mixture of compounds that can directly reach the brain, as described above.

\section{Methods}

Our primary objective is to point to the biological plausibility for the effects of air pollution on a wide range of social behaviors in both human and non-human animals. As a basis for drawing conclusions, we briefly review the 


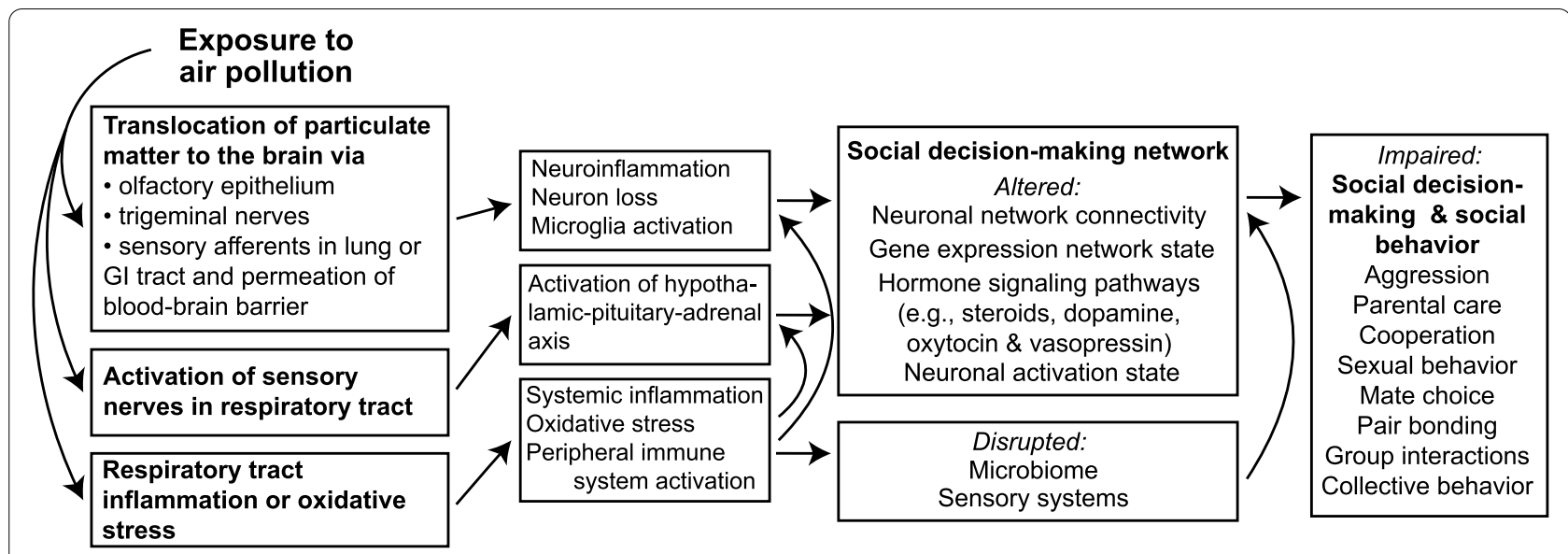

Fig. 1 Potential pathways by which exposure to air pollution could affect social behavior

neural mechanisms of social behavior, focusing on the most relevant neural circuits and neurochemicals, and point to studies that show air pollutants can perturb these systems. Next, we discuss results from experimental studies that examined the effects from any air pollutant exposure on a social behavior-related outcome. To identify these experimental studies, we searched PubMed, Web of Science, and Google Scholar for social behavior-related search terms (social behavior, social interaction, parental care, paternal behavior, maternal behavior, reproductive behavior, sexual behavior, aggressive behavior, aggression, autism, or autistic) combined with one or more air pollutant search terms (particulate matter, ozone, air pollution, aerosol, vehicle emissions, diesel exhaust, nitrogen dioxide, sulfur dioxide, carbon monoxide, lead (with air or gaseous), inhalation exposure, or gaseous pollutants). We also reviewed reference lists from relevant and recently published research. Finally, given the evolutionary conservation of the mechanisms of social behavior, we point to five groups of nonrodent model systems that are well-suited to examine the effects of air pollutant exposure on a diversity of social behaviors and their mechanisms.

\section{Results}

\section{Neurobiological substrates of social behavior are vulnerable to air pollutant exposure}

The specific mechanisms through which air pollutants affect the brain, as well as the neural and molecular mechanisms through which social behavior arises are poorly understood. There are many layers of regulation between the brain and the expression of behavior, meaning there are just as many ways by which these systems can be perturbed by air pollution.

\section{Evolutionarily conserved neural circuits}

The expression of social behavior starts from the perception and evaluation of sensory cues, followed by an integration with the internal physiological state. This requires several layers of coordinated activity across cells in the brain. The first is via neuronal networks, which describes the transmission of electrochemical signals between neurons. An additional layer of activity occurs within gene regulatory networks, a collection of regulatory relationships among genes expressed within brain cells. The existence of gene regulatory networks was put forth following abundant evidence that gene expression profiles in the brain are associated with specific behavioral responses [37]. For social behavior, gene regulatory networks are likely unique given the addition of the social network component to information processing [37]. While spatial and temporal coordination occurs across the brain, there are 14 brain regions that have been wellstudied for their role in social behavior (Table 1), most of which comprise the social decision-making network. In vertebrates, the social decision-making network is a highly conserved fore-/midbrain neural circuit that contains mesolimbic and hypothalamic brain regions [20, 38]. Within the brain regions of the social decision-making network, neuromodulatory systems such as steroid hormones, neuropeptides, and monoamines further integrate neural signals to result in the expression of social behavior.

Potential link to air pollution exposure: Air pollutioninduced changes in social behavior could be driven by neuroinflammation in regions of the social decisionmaking network [26, 40]. Interestingly, neuroinflammation is closely associated with the dysregulation of this network in mood disorders and suicide mortality [41] and substance use disorders [42]. Related to this, 
Table 1 Brain regions of the social decision-making network and their primary known functions in social behavior [39]

\begin{tabular}{|c|c|c|}
\hline medial amygdala & meAMY & aggression, reproduction, parental care, social recognition \\
\hline medial bed nucleus of the stria terminalis & BNST & motivation, parental care, reproduction, stress response \\
\hline preoptic area & POA & aggression, reproduction, parental care \\
\hline lateral septum & LS & $\begin{array}{l}\text { emotional learning, social affiliation/recognition, repro- } \\
\text { duction, parental care }\end{array}$ \\
\hline ventromedial hypothalamus & $\mathrm{VH}$ & aggression, reproduction, parental care \\
\hline anterior hypothalamus & $\mathrm{AH}$ & aggression, reproduction, parental care \\
\hline midbrain periaqueductal gray & PAG & reproduction, vocalization \\
\hline hippocampus & HIP & spatial learning \\
\hline basolateral amygdala & bIAMY & aggression, emotional learning, parental care \\
\hline ventral tegmental area & VTA & motivation, reproduction, parental care \\
\hline striatum & Str & compulsive behavior \\
\hline nucleus accumbens & NAcc & emotional learning, impulsivity, motivation, parental care \\
\hline ventral pallidum & VP & emotional learning, parental care \\
\hline cerebral cortex & $\mathrm{CC}$ & integration, decision-making \\
\hline
\end{tabular}

neuroinflammation arising from peripherally produced pro-inflammatory cytokines can result in 'sickness behavior', an adaptive response to immune activation [43]. Sickness behavior is notably characterized by social withdrawal. Chronic immune activation, such as through long-term air pollution exposure, can exacerbate this behavior and potentially lead to symptoms of depression. Although the cause-effect relationships are far from clear, exposure to fine particulate matter or diesel exhaust can result in an increase in pro-inflammatory cytokines in the striatum and hippocampus of rodents [44-47]. Other changes have been reported as well: Gestational and lactational exposure to traffic-related particulate matter in rats resulted in reduced fractional anisotropy, a measure of white matter tracts, in the hippocampus [48]. Further, ozone exposure in rats was shown to increase neuronal activation in the bed nucleus of the stria terminalis and in the medial amygdala [49], as well as to cause damage and neuronal loss in the hippocampus [50]. Oxidative stress was observed in the hippocampus and amygdala of rats exposed pre- and postnatally to fine particulate matter and/or gaseous pollutants [51]. Additionally, air pollution exposure may affect social behavior by altering hippocampal neurogenesis [52-54].

\section{Neurochemicals}

There are many signaling pathways, acting on both central and peripheral structures, important in the regulation of social behavior. Some of the most well-studied include sex steroids, glucocorticoids, biogenic amines, and the neuropeptides oxytocin and vasopressin [55]. Air pollution is composed of many endocrine disrupting compounds that can perturb these neuroendocrine systems $[24,56]$.
Sex steroid hormones - such as androgens, estrogens, and progestogens - have organizational and activational effects on brain and behavior [57], both of which can be perturbed by pollutant exposure [58]. During critical stages of pre- and postnatal development, testosterone binds to androgen receptors and, after aromatization to estradiol, estrogen receptors. The larger relative amounts of circulating testosterone in males derived from the testes results in signaling cascades that both masculinize and defeminize the developing brain. These organizational effects of steroid hormones on the brain are necessary for the expression of sexually dimorphic social behavior in adulthood [59]. Exposure to endocrine disrupting chemicals during critical periods of brain development can disrupt normal brain organization, as these compounds can act on both androgen and estrogen receptors, even at very low doses [22, 60]. Sex steroid hormones and their receptors also respond via activational effects to social stimuli over both immediate and longer-term timescales to modulate behavior [61]. Within minutes to seconds, steroid hormones can affect behavior via the activation of membrane-bound receptors. Within hours to days, steroid hormones modulate behavior via the activation of nuclear hormone receptors, leading to the transcriptional regulation of target genes. For example, under the 'challenge hypothesis' androgens transiently increase in response to social challenges in some social systems [62, 63], including in humans [64].

Potential link to air pollution exposure: Many known or suspected endocrine disrupting chemicals adhere to diesel exhaust particles (e.g., polycyclic aromatic hydrocarbons, heavy metals) and to particulate matter in general [65], thus diesel exhaust can interact with sex steroid hormone pathways via the release of these adsorbed 
chemicals, from direct effects of the particles themselves, or via exposure to gaseous components such as nitrogen dioxide. Diesel exhaust inhalation exposure has been shown to disrupt testosterone biosynthesis in rats [66], as well as alter serum testosterone levels following prenatal exposure [67]. Further, postnatal inhalation exposure to ultrafine particulate matter can reduce serum testosterone levels in mice [68]. Lastly, diesel exhaust secondary organic aerosol exposure reduces levels of estrogen receptor-alpha in the hypothalamus of mice $[69,70]$.

Glucocorticoids - another class of steroid hormones - are secreted from the adrenal glands following activation of the hypothalamic-pituitary-adrenal axis. Shortterm activation of this axis results in an adaptive stress response that mobilizes energy reserves in the body (e.g., during agonistic social interactions). Responsiveness of the hypothalamic-pituitary-adrenal axis is influenced by social status, such as position in a dominance hierarchy [71], as well as by social factors during development [72].

Potential link to air pollution exposure: Exposures to ozone or particulate matter result in transient activation of the hypothalamic-pituitary-adrenal axis (via activation of sensory nerves in the respiratory tract or inflammation) and a subsequent increase in circulating levels of glucocorticoids [73, 74]. Notably, because social stressors can also dysregulate the hypothalamic-pituitary-adrenal axis, there may be synergistic effects between these stressors and air pollution exposure that further modify glucocorticoid signaling [75].

Biogenic amines (including serotonin and catecholamines such as epinephrine, norepinephrine, and dopamine) are metabolically synthesized in many different tissues, including the brain [76], where they act as neuromodulators. For example, dopaminergic signaling is essential for encoding the salience and rewarding properties of social stimuli and mediates social context-dependent behavior by changing the motivational state $[77,78]$. Dopamine may also serve a critical role in linking social behavior and neuro-immune effects [79]. Serotonin (aka 5-hydroxytryptamine, 5-HT) is another biogenic amine with a role in regulating social behavior. Serotonin is often inversely related to aggressive behavior, particularly expression of the $5-\mathrm{HT}_{1 \mathrm{~A}}$ and $5-\mathrm{HT}_{1 \mathrm{~B}}$ receptor subtypes [80].

Potential link to air pollution exposure: Exposure to diesel exhaust particles can disrupt dopamine neuron function in vitro $[81,82]$. In mice, prenatal inhalation exposure to diesel exhaust results in decreased levels of dopamine metabolites in the striatum and in increased levels of dopamine and its metabolites in the amygdala [83], as well as reduced dopamine turnover in the striatum [84] and increased dopamine levels in the nucleus accumbens [67]. Postnatal inhalation exposure to traffic-derived ultrafine particulate matter increases dopamine turnover in the hippocampus in female mice [47]. In addition, rats exposed to ozone show a decreased number of dopamine neurons in the substantia nigra [85]. Ozone exposure in rats decreased expression of serotonin receptor subtypes $5-\mathrm{HT}_{1 \mathrm{~A}}, 5-\mathrm{HT}_{1 \mathrm{~B}}$, and $5-\mathrm{HT}_{4}$, increased $5-\mathrm{HT}_{2 \mathrm{C}}$ in the hippocampus (a response partly regulated by glucocorticoids) [86], and reduced 5-HT levels in the hypothalamus [87].

Neuropeptides - small proteineous molecules produced in neurons by the processing of a genetically encoded precursor molecule - often act as neuromodulators. The nonapeptides oxytocin, vasopressin, and their non-mammalian homologs are exceptionally well studied for their role in mediating social behavior, in particular social attachment, recognition, affiliation, and parental behavior [88, 89]. These effects are highly conserved across species [90]. In addition, several links have been made between oxytocin signaling and autism spectrum disorder. In two different mice models, mutations in human autism risk genes resulted in impaired oxytocin signaling and autistic-like behavior [91, 92].

Potential link to air pollution exposure: Pre- and postnatal exposure in rats to fine particulate matter and/or gaseous pollutants results in decreased oxytocin receptor expression in the amygdala and hippocampus [51]. In mice, adult exposure to diesel exhaust secondary organic aerosols results in reduced gene expression of the oxytocin receptor in the hypothalamus [69]. In addition, there is growing evidence that oxytocin and vasopressin pathways are perturbed by endocrine disrupting chemicals [93], many of which are present in outdoor air.

\section{Effects of air pollutants on social behavior}

As formalized in the developmental origins of adult disease hypothesis, exposure to environmental stressors during critical windows can affect disease susceptibility later in life [94]. In addition to potential perturbations during development, social behavior can also be affected by exposures later in life. Epidemiological studies have examined the effects of air pollution on social behaviorrelated outcomes during development and in adults, and experimental studies have begun to provide support for these effects. Thus far, these experimental studies are limited to rodent model systems, results of which are briefly summarized below.

\section{Developmental exposures}

Autism spectrum disorders are a group of disabilities that arise during development and affect social interactions and communication throughout adolescence and adulthood. Both genetic and environmental factors contribute to their etiology [95]. Several recent 
systematic reviews and meta-analyses have assessed the epidemiologic evidence base for the effects of air pollution exposure on autism spectrum disorders [96-98]. While noting limitations in the available evidence, each of these reviews identified an association between prenatal exposure to fine particulate matter and diagnoses of autism spectrum disorders. Furthermore, a separate study reported an association between social responsiveness in children and exposure to polycyclic aromatic hydrocarbons during prenatal development [17]. In general, based on the available studies described below, experimental animal studies have reported concordant results - inhalation exposure to air pollutants during development, including particulate matter, consistently affects aspects of social behavior in rodent models. These effects are often observed in males but not females, suggesting a sex bias in susceptibility. Diagnoses of several neurodevelopmental disorders, including autism spectrum disorders, are more prevalent in males. There is a wide range of likely mechanisms underlying this sex specificity, including disruption of androgenic signaling pathways during development and early maternal immune activation, both of which may arise from air pollutant exposure $[99,100]$.

In two studies, exposure to fine particulate matter during pre/postnatal development resulted in impaired social behavior in male but not female mice $[46,101]$. In addition, treatment reduced social approach and preference for novel conspecifics, but did not affect social recognition [46, 101]. In a separate study, postnatal exposure to traffic-derived ultrafine particulate matter resulted in reduced social novelty preference in male but not female mice, which is likely related to abnormal testosterone levels during development [68]. In male rats, pre- and postnatal exposure to traffic-derived particulate matter reduced levels of social play, allogrooming, and nest building performance [48]. Finally, pre- and postnatal exposure to a mixture of fine particulate matter and gaseous pollutants impaired social novelty preference in rats [51]. Adult mice exposed pre- and postnatally to diesel exhaust showed reduced social interactions, decreased social novelty preference, and failed to habituate to a social odor [70, 102]. However, a similar study of diesel exhaust particles reported null results [103], potentially suggesting an important contribution of the gaseous component [104]. Finally, male mice prenatally exposed to diesel exhaust showed increased social isolation-induced territorial aggression [67]. The specific mechanisms through which developmental air pollutant exposures affect social behavior, with increased susceptibility in males, remain unclear but likely arise from interactions between the endocrine and immune systems [100].

\section{Adult exposures}

Several epidemiological studies have suggested that short-term changes in air pollutant exposure can affect human behavior. For example, increased levels of fine particulate matter and ozone were found to associate with heightened levels of violent, but not non-violent, crime $[105,106]$, a potential effect on aggressive behavior. In addition, a recent systematic review and metaanalysis reported that short-term exposure to nitrogen dioxide, but not to ozone, sulfur dioxide, or particulate matter, was positively associated with depression (which includes social withdrawal and isolation) [107]. A different meta-analysis found an association between longterm exposure ( $>6$ months) to fine particulate matter and depression [108]. Both reviews have pointed to the limitations in the evidence and suggest that more high-quality studies are needed to assess the effects of air pollution on mental health outcomes.

Few experimental studies have assessed effects of adult inhalation exposure to air pollutants on social behavior. Mice dams exposed to secondary organic aerosols from diesel exhaust showed decreased maternal performance [69]. In addition, there is evidence from mice that adult exposure to ozone, sulfur dioxide, or heavy metals from vehicle dust can inhibit aggressive behavior [109-111] and that ozone exposure can impair social interactions more generally [112]. Importantly, air pollution could also affect social behavior in adult animals by impairing sensory perception. For example, in species where chemical signals, such as pheromones, are important for mate attraction or social aggregation, chemical reactions with air pollution (oxidation from ozone, in particular) could shorten the distance signals can travel or impair receptor binding [113].

\section{Emerging research areas}

There are several emerging and shared research areas within both the study of social behavior and in air pollution toxicology. For example, the role of the microbiome has become prominent. Microbes interact with their host through a variety of signaling pathways, including via the production of microbial-associated molecular patterns, neurotransmitters, hormones, metabolites, and immune cells. Host microbes are necessary for neurodevelopment, impact the central nervous system throughout adulthood, and have been implicated in social behavior [114-116]. Air pollution exposure appears to disrupt the microbiome, potentially via inflammation and altered epithelial cell permeability in the gut $[117,118]$. The interaction between microbes and air pollution has the 
potential to bidirectionally impact social behavior, yet directly linking alterations in the microbiome to function and host health is challenging. Another important research area is in neuroepigenetics. Regulation of the chromatin of neurons affects behavior, and this regulation can be affected by environmental exposures [119]. In addition, environmental exposures can result in transgenerational epigenetic modifications with impacts on behavior $[120,121]$, though the link between air pollutants and social behavior has not yet been explicitly made. More broadly, emerging approaches toward the study of environmental exposures and neuropsychiatric diseases have been recently outlined [122].

\section{Translational potential}

While important as model systems, laboratory rodents are limited in their behavioral repertoire. In addition to the benefits of a comparative approach (discussed below), examining the effects of air pollution exposure on diverse species allows an analysis of effects on a broad spectrum of social behaviors and their neurobiological mechanisms. Here, we highlight zebra finch, zebrafish, frogs and anoles, bees, and fruit flies as complementary model systems (Fig. 2). For most of these species, there is a full suite of genomic and molecular tools available that have allowed them to serve as model systems in social neuroscience $[123,124]$. Employing these species in studies on the effects of air pollutants on social behavior can serve as a bridge between reductionist laboratory experiments and field-based ecotoxicology assays [125]. For example,

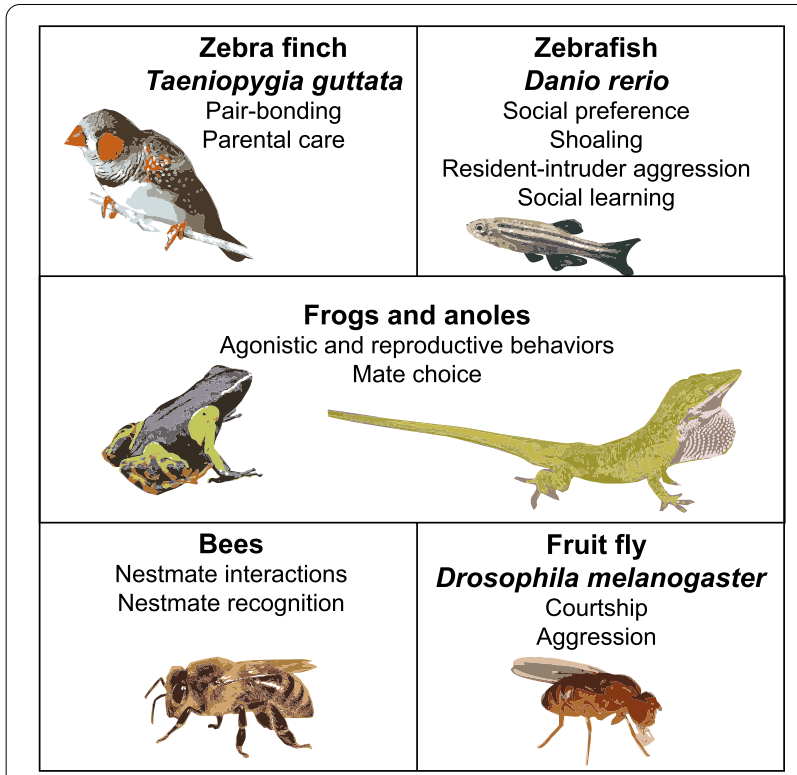

Fig. 2 Complementary model systems in which to examine the effects of exposure to air pollution on social behavior while these species are used as models in the laboratory, they can also be collected in the wild, allowing for a realistic profiling of their exposome to characterize cumulative exposure [126]. Integrating the metabolome, proteome, transcriptome, and epigenome with behavior assays following both field and laboratory-based exposures can provide a systems-level view of the effects of inhaled pollutants [126]. An important aspect to these models, however, is their lack of, or distinct pulmonary systems compared to mammals. As the lungs are the primary target for air pollution, it will be critical to identify how different respiratory systems respond to air pollutant exposure and to clearly define the translational potential between humans and non-mammalian model systems.

\section{Zebra finch}

As canaries in the coal mine, birds have highly efficient respiratory systems that make them more sensitive to air pollutants compared to many mammalian species [127]. In addition, entire flocks can be exposed to environmentally-relevant mixtures of air pollutants under controlled conditions [128]. One of the most studied birds in social neuroscience is the zebra finch, Taeniopygia guttata. The zebra finch is monogamous, allowing for the study of the effects of air pollutants on pair-bonding and parental care behaviors in both males and females. Given evidence that the molecular underpinnings of monogamy are in part highly conserved across vertebrates [129], many neuromolecular mechanisms affected in zebra finch are likely shared with humans. Thus far, the limited number of studies available that employ zebra finch in toxicology primarily focus on dietary exposure and reproductive endpoints [130].

\section{Zebrafish}

The zebrafish, Danio rerio, may be a less obvious model system for studying air pollutant exposure compared to birds and cannot capture effects of inhalation, but nonetheless it holds great promise as a model system. In one study, zebrafish were used to examine effects of solubilized fine particulate matter on locomotor behavior [131]. This study and others suggest that the skin response in larval zebrafish can be predictive of mammalian lung epithelial responses [132]. Zebrafish are widely used as a model throughout biomedical science and specifically in the study of brain disorders [133-135]. In addition, they are being employed as a model to study the mechanistic basis of social behavior [136, 137]. Many assays have been developed to examine social behavior in zebrafish, including tests of social preference, shoaling, residentintruder aggression, and social learning [138], including the use of sophisticated high-throughput video tracking methods [139, 140]. While zebrafish social behavior is 
not yet frequently examined in toxicity assays of air pollution mixtures, several studies have examined the effects of endocrine disrupting compounds [141, 142] and pharmaceuticals $[139,143]$ on social behavior.

\section{Frogs and Anoles}

Amphibians may be particularly sensitive to air pollutants given their potential for increased respiratory exposure due to gas exchange across the skin. Physiological effects of ozone exposure have been investigated in amphibians and reptiles, but to our knowledge no studies have examined effects on social behavior. Female mate choice assays, which are very robust in frogs, could be employed to examine whether air pollutants interfere with the hormonal modulation of behavior [144, 145]. In addition, Anolis lizards are amenable to assays of agonistic and reproductive behaviors [146, 147]. Both frogs and anoles are frequently used as model systems to examine the mechanistic basis of social behavior [147-150].

\section{Bees}

Honeybees, Apis mellifera, are highly social, living in colonies of thousands of individuals with distinct roles within the group. Honeybees have a long history as a unique model in neuroscience to study olfactory learning, and more recently as a model to study cognition [151]. Despite differences in neural architecture, the deep evolutionary conservation of social behavior genes makes mechanisms regulating behavior in bees relevant to humans [152, 153]. For example, similarities were found between autism-related genes in humans and socially unresponsive honeybees [154]. Honeybees have been used as biomonitors of air pollutants, and a limited number of studies have examined pollutant effects on olfactory learning and memory [155]. Effects on social behavior from air pollutants have yet to be investigated, however a recent study found an association between particulate matter air pollution and flower visitation, expression of stress-related genes, and survival in the Giant Asian honeybee, Apis dorsata [156]. Given the ability to track and monitor individual interactions at high spatial and temporal resolution [157], honeybees could become a powerful model system to examine effects of air pollution. Similarly, bumblebees, Bombus sp. species, share many of the advantages of honeybees as a model system but with significantly smaller colonies. In addition, standardized microcolonies of bumblebees can be studied under defined laboratory conditions, allowing for large sample size and replication capacities [158].

\section{Fruit flies}

The fruit fly, Drosophila melanogaster, is a classic genetic model system with an unparalleled molecular-genetic toolkit, as well as methods for high-throughput phenotyping of social behavior, such as courtship [159] and aggressive behavior [160]. The effects of indoor air pollutants on gene expression and locomotor behavior have been examined [161], suggesting this model is highly amenable to high-throughput testing of the effects of air pollutants on social behavior. Specifically, inhalation exposure to toluene or formaldehyde induced gene expression changes similar to those reported in mammals, affecting pathways related to stress and immune responses.

\section{Discussion}

Great strides are being made in new approach methodologies in risk assessment and hazard identification, such as integrating in vitro and in silico approaches, and in -omics and high-throughput screening technologies. These new methods can produce a vast amount of mechanistic data for environmental chemicals, but without behavioral data it is challenging to assess the adversity of the outcomes. Thus, it has been suggested that behavioral outcomes be used as an organizing principle in neurotoxicology $[162,163]$. While behavioral studies are critical to understanding the context of mechanistic effects from pollutant exposure, there is also a longstanding push to replace, reduce, or refine animal use in research. For example, the U.S. EPA recently called for an elimination of all mammal study requests and funding by 2035. To make progress toward the goal of limiting animal research, an improved understanding of the degree to which adverse effects and mode of action of air pollutant exposures are conserved across animals is needed. We suggest that this could be gained by a comparative and translational approach that expands both the species studied and the behavioral assays employed.

While research in laboratory rodents has driven much of our understanding of neuroscience and neurotoxicology, there are numerous potential advantages to complementing this body of knowledge by the study of more evolutionarily diverse species [123, 124, 164-166]. First, a phylogenetic comparative approach utilizing species across animal lineages that range in evolutionary distance to one another allows for hypothesis testing [20, $152,167]$. Further, clearly defining the conserved initiating events and mode of action though which air pollutant exposure may lead to adverse social-behavioral effects can help the field move toward more predictive frameworks $[168,169]$, an important initiative given that many more air pollutants and mixtures of pollutants exist than can be tested by behavioral assays. Finally, an additional benefit to studying the effects of air pollutants on social behavior in a broader range of species is that it can provide insight into possible causes of wildlife population 
declines worldwide. For example, though the mechanisms are unknown, ambient ozone concentrations have been associated with declines in bird populations in the U.S. [170].

Much progress has been made toward understanding the neural and molecular basis of social behavior across a wide range of species. More often than not, this research has shown that the mechanisms regulating social behavior are highly conserved across vertebrates and even beyond. However, this insight has not yet been widely integrated in applied research. There is a great opportunity to apply perspectives from evolutionary neuroscience and genetics toward the study of the behavioral and neurodevelopmental effects of environmental chemicals, and specifically toward examining the effects of air pollutants on social behavior. In addition, in humans, the adverse effects of air pollutants result from interactions among multiple stressors, many of which are non-chemical and psychosocial in nature (e.g., socioeconomic disparities, lack of family stability) $[74,171,172]$. There are opportunities within the model systems described above to simulate social stress, such as through dominance hierarchies, and to investigate the interactive effects from air pollutants.

\section{Conclusions}

Given the overlap between conserved mechanisms of social behavior and alterations from air pollutants, such as modulation of the dopaminergic reward system, air pollution has the potential to impact a wide array of social behaviors in both humans and wildlife. Moving forward, it will be important to develop a framework that spans beyond neurodevelopmental and neuropsychiatric disorders to investigate effects of air pollutants on social behavior in a wider range of species, brain regions, and neurochemical pathways. In general, increased collaboration between neuroscientists, geneticists, and environmental health scientists has the potential to further all fields, in addition to benefitting public health [122].

\footnotetext{
Acknowledgements

We thank Drs. Andrea Gore, Mbemba Jabbi, Laura K. Fonken, Katie O'Shaughnessy, David Lehmann, Andrew Hotchkiss, and John Vandenberg for help improving the manuscript. Images used in Fig. 2 were modified from the original. Attributions for original images: zebra finch, Dennis Jarvis (CC BY-SA 2.0); zebrafish, Oregon State University (CC BY-SA 2.0); bee and frog, Charles J. Sharp (CC BY-SA 3.0); fly, Sanjay Acharya (CC BY-SA 4.0). This manuscript has been reviewed by the U.S. EPA and approved for publication. Approval does not necessarily signify that the contents reflect the views or opinions of the U.S. EPA, nor does mention of trade names or commercial products constitute endorsement or recommendation for use.
}

\section{Authors' contributions}

Conceptualization: CAW and HAH; Writing - original draft preparation: CAW; Writing - review and editing: CAW and HAH. The author(s) read and approved the final manuscript.
Funding

This work was supported by National Science Foundation grant IOS 1354942 (to $\mathrm{HAH}$ ).

Availability of data and materials

Not applicable.

\section{Declarations}

Ethics approval and consent to participate

Not applicable.

Consent for publication

Not applicable.

Competing interests

The authors declare that they have no competing interests.

\section{Author details}

${ }^{1}$ Center for Public Health and Environmental Assessment, U.S. Environmental Protection Agency, Durham, NC, USA. ${ }^{2}$ Department of Integrative Biology, The University of Texas At Austin, Austin, TX, USA. ${ }^{3}$ Institute for Cellular and Molecular Biology, The University of Texas At Austin, Austin, TX, USA. ${ }^{4}$ Institute for Neuroscience, The University of Texas At Austin, Austin, TX, USA.

Received: 14 April 2021 Accepted: 18 June 2021

Published online: 25 June 2021

\section{References}

1. Tessum CW, Apte JS, Goodkind AL, Muller NZ, Mullins KA, Paolella $D A$, et al. Inequity in consumption of goods and services adds to racial-ethnic disparities in air pollution exposure. Proc Natl Acad Sci. 2019;116(13):6001-6.

2. Landrigan PJ. Air pollution and health. Lancet Public Health. 2017;2(1):E4-5.

3. Cohen AJ, Brauer M, Burnett R, Anderson HR, Frostad J, Estep K, et al. Estimates and 25-year trends of the global burden of disease attributable to ambient air pollution: an analysis of data from the Global Burden of Diseases Study 2015. Lancet. 2017;389(10082):1907-18.

4. Block ML, Elder A, Auten RL, Bilbo SD, Chen HL, Chen JC, et al. The outdoor air pollution and brain health workshop. Neurotoxicology. 2012;33(5):972-84.

5. Genc S, Zadeoglulari Z, Fuss SH, Genc K. The adverse effects of air pollution on the nervous system. J Toxicol. 2012;2012:782462.

6. Oberdorster G, Utell MJ. Ultrafine particles in the urban air: to the respiratory tract-and beyond? Environ Health Perspect. 2002;1 10(8):A440-1.

7. Ritz B, Liew Z, Yan Q, Cui X, Virk J, Ketzel M, et al. Air pollution and autism in Denmark. Environ Epidemiol. 2018;2(4).

8. Volk HE, Lurmann F, Penfold B, Hertz-Picciotto I, McConnell R. Trafficrelated air pollution, particulate matter, and autism. JAMA Psychiat. 2013;70(1):71-7.

9. Pagalan L, Bickford C, Weikum W, Lanphear B, Brauer M, Lanphear N, et al. Association of prenatal exposure to air pollution with autism spectrum disorder. JAMA Pediatr. 2019;173(1):86-92.

10. Raz R, Levine H, Pinto O, Broday DM, Yuval, Weisskopf MG. Traffic-related air pollution and autism spectrum disorder: a population-based nested case-control study in Israel. Am J Epidemiol. 2018;187(4):717-25.

11. Volk HE, Hertz-Picciotto I, Delwiche L, Lurmann F, McConnell R. Residential proximity to freeways and autism in the CHARGE study. Environ Health Perspect. 2011;119(6):873-7.

12. Khan A, Plana-Ripoll O, Antonsen S, Brandt J, Geels C, Landecker H, et al. Environmental pollution is associated with increased risk of psychiatric disorders in the US and Denmark. Plos Biol. 2019;17(8).

13. Lim Y-H, Kim H, Kim JH, Bae S, Park HY, Hong Y-C. Air pollution and symptoms of depression in elderly adults. Environ Health Persp. 2012;120(7):1023-8.

14. Cory-Slechta DA, Sobolewski M, Marvin E, Conrad K, Merrill A, Anderson $T$, et al. The impact of inhaled ambient ultrafine particulate matter on 
developing brain: potential importance of elemental contaminants. Toxicol Pathol. 2019;47(8):976-92.

15. Allen JL, Oberdorster G, Morris-Schaffer K, Wong C, Klocke C, Sobolewski M, et al. Developmental neurotoxicity of inhaled ambient ultrafine particle air pollution: Parallels with neuropathological and behavioral features of autism and other neurodevelopmental disorders. Neurotoxicology. 2017;59:140-54.

16. Costa LG, Cole TB, Dao K, Chang Y-C, Coburn J, Garrick JM. Effects of air pollution on the nervous system and its possible role in neurodevelopmental and neurodegenerative disorders. Pharmacol Therapeut. 2020;210.

17. Margolis AE, Herbstman JB, Davis KS, Thomas VK, Tang D, Wang Y, et al. Longitudinal effects of prenatal exposure to air pollutants on selfregulatory capacities and social competence. J Child Psychol Psychiatry. 2016;57(7):851-60.

18. Lu JG, Lee JJ, Gino F, Galinsky AD. Polluted morality: air pollution predicts criminal activity and unethical behavior. Psychol Sci. 2018;29(3):340-55.

19. Mielke HW, Zahran S. The urban rise and fall of air lead $(\mathrm{Pb})$ and the latent surge and retreat of societal violence. Environ Int. 2012:43:48-55.

20. O'Connell LA, Hofmann HA. Genes, hormones, and circuits: An integrative approach to study the evolution of social behavior. Front Neuroendocrin. 2011;32(3):320-35.

21. Clotfelter ED, Bell AM, Levering KR. The role of animal behaviour in the study of endocrine-disrupting chemicals. Anim Behav. 2004;68:665-76.

22. Gore AC, Krishnan K, Reilly MP. Endocrine-disrupting chemicals: Effects on neuroendocrine systems and the neurobiology of social behavior. Horm Behav. 2019;111:7-22.

23. Vom Saal FS, Woodruff TJ, Soto AM, Skakkebaek NE, Gore AC, Doan LL, et al. Endocrine-disrupting chemicals and public health protection: a statement of principles from The Endocrine Society. Endocrinology. 2012;153(9):4097-110.

24. Annamalai J, Namasivayam V. Endocrine disrupting chemicals in the atmosphere: their effects on humans and wildlife. Environ Int. 2015;76:78-97.

25. Darbre PD. Overview of air pollution and endocrine disorders. Int J Gen Med. 2018;11:191-207.

26. Jayaraj RL, Rodriguez EA, Wang Y, Block ML. Outdoor ambient air pollution and neurodegenerative diseases: the neuroinflammation hypothesis. Curr Environ Health Rep. 2017;4(2):166-79.

27. World Health Organization. Fact Sheet: Ambient (outdoor) air pollution [Available from: https://www.who.int/en/news-room/fact-sheets/ detail/ambient-(outdoor)-air-quality-and-health. Accessed 6 Jan 2021.

28. Block ML, Calderon-Garciduenas L. Air pollution: mechanisms of neuroinflammation and CNS disease. Trends Neurosci. 2009;32(9):506-16.

29. Peters A, Veronesi B, Calderon-Garciduenas L, Gehr P, Chen LC, Geiser $\mathrm{M}$, et al. Translocation and potential neurological effects of fine and ultrafine particles a critical update. Part Fibre Toxicol. 2006;3:13.

30. U.S. EPA. Integrated Science Assessment (ISA) for Particulate Matter (Final Report, Dec 2019). Washington, DC: U.S. Environmental Protection Agency; 2019

31. Elder A, Gelein R, Silva V, Feikert T, Opanashuk L, Carter J, et al. Translocation of inhaled ultrafine manganese oxide particles to the central nervous system. Environ Health Perspect. 2006;114(8):1172-8.

32. Block ML, Zecca L, Hong JS. Microglia-mediated neurotoxicity: uncovering the molecular mechanisms. Nat Rev Neurosci. 2007;8(1):57-69.

33. Perry VH. The influence of systemic inflammation on inflammation in the brain: implications for chronic neurodegenerative disease. Brain Behav Immun. 2004;18(5):407-13.

34. Mumaw CL, Levesque S, McGraw C, Robertson S, Lucas S, Stafflinger $\mathrm{JE}$, et al. Microglial priming through the lung-brain axis: the role of air pollution-induced circulating factors. FASEB J. 2016;30(5):1880-91.

35. Klocke C, Sethi S, Lein PJ. The developmental neurotoxicity of legacy vs. contemporary polychlorinated biphenyls (PCBs): similarities and differences. Environ Sci Pollution Res. 2019;27(9):8885-96.

36. Lehmann GM, Christensen K, Maddaloni M, Phillips LJ. Evaluating health risks from inhaled polychlorinated biphenyls: research needs for addressing uncertainty. Environ Health Persp. 2015;123(2):109-13.

37. Sinha S, Jones BM, Traniello IM, Bukhari SA, Halfon MS, Hofmann HA, et al. Behavior-related gene regulatory networks: A new level of organization in the brain. Proc Natl Acad Sci U S A. 2020
38. O'Connell LA, Hofmann HA. Evolution of a vertebrate social decisionmaking network. Science. 2012;336(6085):1154-7.

39. O'Connell LA, Hofmann HA. The vertebrate mesolimbic reward system and social behavior network: a comparative synthesis. J Comp Neurol. 2011;519(18):3599-639.

40. Kristiansson M, Sorman K, Tekwe C, Calderon-Garciduenas L. Urban air pollution, poverty, violence and health-neurological and immunological aspects as mediating factors. Environ Res. 2015;140:511-3.

41. Jabbi M, Arasappan D, Eickhoff SB, Strakowski SM, Nemeroff CB, Hofmann HA. Neuro-transcriptomic signatures for mood disorder morbidity and suicide mortality. J Psychiatr Res. 2020;127:62-74.

42. Mayfield J, Ferguson L, Harris RA. Neuroimmune signaling: a key component of alcohol abuse. Curr Opin Neurobiol. 2013;23(4):513-20.

43. Dantzer R, O'Connor JC, Freund GG, Johnson RW, Kelley KW. From inflammation to sickness and depression: when the immune system subjugates the brain. Nat Rev Neurosci. 2008:9(1):46-56.

44. Fonken LK, Xu X, Weil ZM, Chen G, Sun Q, Rajagopalan S, et al. Air pollution impairs cognition, provokes depressive-like behaviors and alters hippocampal cytokine expression and morphology. Mol Psychiatr. 2011:16(10):987-95.

45. Gerlofs-Nijland ME, van Berlo D, Cassee FR, Schins RPF, Wang K, Campbell A. Effect of prolonged exposure to diesel engine exhaust on proinflammatory markers in different regions of the rat brain. Part Fibre Toxicol. 2010;7.

46. Li K, Li L, Cui B, Gai ZH, Li QY, Wang SM, et al. Early postnatal exposure to airborne fine particulate matter induces autism-like phenotypes in male rats. Toxicol Sci. 2018:162(1):189-99.

47. Allen JL, Liu X, Pelkowski S, Palmer B, Conrad K, Oberdorster G, et al. Early postnatal exposure to ultrafine particulate matter air pollution: persistent ventriculomegaly, neurochemical disruption, and glial activation preferentially in male mice. Environ Health Perspect. 2014;122(9):939-45.

48. Nephew BC, Nemeth A, Hudda N, Beamer G, Mann P, Petitto J, et al. Traffic-related particulate matter affects behavior, inflammation, and neural integrity in a developmental rodent model. Environ Res. 2020;183.

49. Gackiere F, Saliba L, Baude A, Bosler O, Strube C. Ozone inhalation activates stress-responsive regions of the CNS. J Neurochem. 2011;117(6):961-72.

50. Rivas-Arancibia S, Guevara-Guzman R, Lopez-Vidal Y, RodriguezMartinez E, Zanardo-Gomes M, Angoa-Perez M, et al. Oxidative stress caused by ozone exposure induces loss of brain repair in the hippocampus of adult rats. Toxicol Sci. 2010;113(1):187-97.

51. Emam B, Shahsavani A, Khodagholi F, Zarandi SM, Hopke PK, Hadei $M$, et al. Effects of PM2.5 and gases exposure during prenatal and early-life on autism-like phenotypes in male rat offspring. Part Fibre Toxicol. 2020;17(1).

52. Woodward NC, Haghani A, Johnson RG, Hsu TM, Saffari A, Sioutas C, et al. Prenatal and early life exposure to air pollution induced hippocampal vascular leakage and impaired neurogenesis in association with behavioral deficits. Transl Psychiatry. 2018:8(1)

53. Coburn JL, Cole TB, Dao KT, Costa LG. Acute exposure to diesel exhaust impairs adult neurogenesis in mice: prominence in males and protective effect of pioglitazone. Arch Toxicol. 2018:92(5):1815-29.

54. Patten KT, González EA, Valenzuela A, Berg E, Wallis C, Garbow JR, et al. Effects of early life exposure to traffic-related air pollution on brain development in juvenile Sprague-Dawley rats. Transl Psychiatry. 2020;10(1).

55. Weitekamp CA, Hofmann HA. Brain systems underlying social behavior. In: Kaas JH, editor. Evolution of nervous systems. Volume 1: The evolution of the nervous systems in nonmammalian vertebrates. 2nd ed. 2017. p. 327-34.

56. La Merrill MA, Vandenberg LN, Smith MT, Goodson W, Browne P, Patisaul $\mathrm{HB}$, et al. Consensus on the key characteristics of endocrine-disrupting chemicals as a basis for hazard identification. Nat Rev Endocrinol. 2020;16(1):45-57.

57. Arnold A. Organizational and activational effects of sex steroids on brain and behavior: a reanalysis. Horm Behav. 1985;19(4):469-98.

58. Rosenfeld CS, Denslow ND, Orlando EF, Gutierrez-Villagomez JM, Trudeau VL. Neuroendocrine disruption of organizational and 
activational hormone programming in poikilothermic vertebrates. J Toxicol Environ Health Part B. 2017;20(5):276-304.

59. McCarthy MM, Nugent BM, Lenz KM. Neuroimmunology and neuroepigenetics in the establishment of sex differences in the brain. Nat Rev Neurosci. 2017;18(8):471-84

60. Myers JP, Zoeller RT, Welshons WV, vom Saal FS, Soto AM, Shioda T, et al. Hormones and endocrine-disrupting chemicals: low-dose effects and nonmonotonic dose responses. Endocr Rev. 2012;33(3):378-455.

61. Balthazart J, Choleris E, Remage-Healey L. Steroids and the brain: 50 years of research, conceptual shifts and the ascent of non-classical and membrane-initiated actions. Horm Behav. 2018;99:1-8.

62. Wingfield JC, Hegner RE, Dufty AM, Ball GF. The "challenge hypothesis": theoretical implications for patterns of testosterone secretion, mating systems, and breeding strategies. Am Nat. 1990;136(6):829-46.

63. Moore IT, Hernandez J, Goymann W. Who rises to the challenge? Testing the Challenge Hypothesis in fish, amphibians, reptiles, and mammals. Horm Behav. 2020;123.

64. Wingfield JC. The challenge hypothesis: where it began and relevance to humans. Horm Behav. 2017;92:9-12.

65. Sidhu S, Gullett B, Striebich R, Klosterman J, Contreras J, DeVito M. Endocrine disrupting chemical emissions from combustion sources: diesel particulate emissions and domestic waste open burn emissions. Atmos Environ. 2005;39(5):801-11.

66. Ramdhan DH, Ito Y, Yanagiba Y, Yamagishi N, Hayashi Y, Li CM, et al. Nanoparticle-rich diesel exhaust may disrupt testosterone biosynthesis and metabolism via growth hormone. Toxicol Lett. 2009;191(2-3):103-8.

67. Yokota S, Oshio S, Moriya N, Takeda K. Social isolation-induced territorial aggression in male offspring is enhanced by exposure to diesel exhaust during pregnancy. Plos One. 2016;11(2).

68. Sobolewski M, Anderson T, Conrad K, Marvin E, Klocke C, Morris-Schaffer K, et al. Developmental exposures to ultrafine particle air pollution reduces early testosterone levels and adult male social novelty preference: risk for children's sex-biased neurobehavioral disorders. Neurotoxicology. 2018;68:203-11.

69. Win-Shwe TT, Fujitani Y, Kyi-Tha-Thu C, Furuyama A, Michikawa T, Tsukahara S, et al. Effects of diesel engine exhaust origin secondary organic aerosols on novel object recognition ability and maternal behavior in BALB/C mice. Int J Env Res Pub He. 2014;11(11):11286-307.

70. Win-Shwe TT, Kyi-Tha-Thu C, Moe Y, Fujitani Y, Tsukahara S, Hirano S. Exposure of BALB/c Mice to Diesel Engine Exhaust Origin Secondary Organic Aerosol (DE-SOA) during the developmental stages impairs the social behavior in adult life of the males. Front Neurosci-Switz. 2016:9.

71. Summers CH, Watt MJ, Ling TL, Forster GL, Carpenter RE, Korzan WJ, et al. Glucocorticoid interaction with aggression in non-mammalian vertebrates: reciprocal action. Eur J Pharmacol. 2005;526(1-3):21-35.

72. Hostinar CE, Gunnar MR. Future directions in the study of social relationships as regulators of the HPA axis across development. J Clin Child Adolesc Psychol. 2013;42(4):564-75.

73. Snow SJ, Henriquez AR, Costa DL, Kodavanti UP. Neuroendocrine regulation of air pollution health effects: emerging insights. Toxicol Sci. 2018;164(1):9-20

74. Thomson EM. Air pollution, stress, and allostatic load: linking systemic and central nervous system impacts. J Alzheimers Dis. 2019;69(3):597-614.

75. Clougherty JE, Kubzansky LD. A framework for examining social stress and susceptibility to air pollution in respiratory health. Environ Health Persp. 2009;117(9):1351-8

76. Borowsky B, Adham N, Jones KA, Raddatz R, Artymyshyn R, Ogozalek KL, et al. Trace amines: Identification of a family of mammalian $G$ proteincoupled receptors. Proc Natl Acad Sci. 2001;98(16):8966-71.

77. Weitekamp CA, Nguyen J, Hofmann HA. Social context affects behavior, preoptic area gene expression, and response to D2 receptor manipulation during territorial defense in a cichlid fish. Genes Brain Behav. 2017;16(6):601-11.

78. Young KA, Gobrogge KL, Wang Z. The role of mesocorticolimbic dopamine in regulating interactions between drugs of abuse and social behavior. Neurosci Biobehav Rev. 2011;35(3):498-515

79. Kopec AM, Smith CJ, Bilbo SD. Neuro-immune mechanisms regulating social behavior: dopamine as mediator? Trends Neurosci. 2019;42(5):337-48.
80. Nelson RJ, Trainor BC. Neural mechanisms of aggression. Nat Rev Neurosci. 2007;8(7):536-46.

81. Levesque S, Taetzsch T, Lull ME, Kodavanti U, Stadler K, Wagner A, et al. Diesel exhaust activates and primes microglia: air pollution, neuroinflammation, and regulation of dopaminergic neurotoxicity. Environ Health Persp. 2011;119(8):1149-55.

82. Levesque S, Taetzsch T, Lull ME, Johnson JA, McGraw C, Block ML. The role of MAC1 in diesel exhaust particle-induced microglial activation and loss of dopaminergic neuron function. J Neurochem. 2013;125(5):756-65

83. Yokota S, Moriya N, Iwata M, Umezawa M, Oshio S, Takeda K. Exposure to diesel exhaust during fetal period affects behavior and neurotransmitters in male offspring mice. J Toxicol Sci. 2013;38(1):13-23.

84. Suzuki T, Oshio S, Iwata M, Saburi H, Odagiri T, Udagawa T, et al. In utero exposure to a low concentration of diesel exhaust affects spontaneous locomotor activity and monoaminergic system in male mice. Part Fibre Toxicol. 2010;7:7.

85. Santiago-Lopez D, Bautista-Martinez JA, Reyes-Hernandez Cl, AguilarMartinez M, Rivas-Arancibia S. Oxidative stress, progressive damage in the substantia nigra and plasma dopamine oxidation, in rats chronically exposed to ozone. Toxicol Lett. 2010;197(3):193-200.

86. Rose M, Filiatreault A, Guénette J, Williams A, Thomson EM. Ozone increases plasma kynurenine-tryptophan ratio and impacts hippocampal serotonin receptor and neurotrophic factor expression: role of stress hormones. Environ Res. 2020;185.

87. Huitrón-Reséndiz S, Custodio-Ramírez V, Escalante-Membrillo C, González-Piña R, Paz C. Sleep alterations and brain regional changes of serotonin and its metabolite in rats exposed to ozone. Neurosci Lett. 1994;177(1-2):119-22.

88. Insel T. Neuropeptides and the evolution of social behavior. Curr Opin Neurobiol. 2000;10(6):784-9.

89. Young LJ, Pitkow LJ, Ferguson JN. Neuropeptides and social behavior: animal models relevant to autism. Mol Psychiatr. 2002;7(S2):S38-9.

90. Johnson ZV, Young LJ. Oxytocin and vasopressin neural networks: Implications for social behavioral diversity and translational neuroscience. Neurosci Biobehav Rev. 2017;76:87-98.

91. Hörnberg H, Pérez-Garci E, Schreiner D, Hatstatt-Burklé L, Magara F, Baudouin $\mathrm{S}$, et al. Rescue of oxytocin response and social behaviour in a mouse model of autism. Nature. 2020;584(7820):252-6.

92. Peñagarikano O, Lázaro MT, Lu X-H, Gordon A, Dong H, Lam HA, et al. Exogenous and evoked oxytocin restores social behavior in theCntnap2mouse model of autism. Sci Transl Med. 2015;7(271):271 ra8-ra8.

93. Patisaul HB. Endocrine disruption of vasopressin system and related behaviors. Front Endocrinol. 2017;8.

94. Hanson M, Thompson C, Slechta DC, Suk W, Sly PD, Landrigan PJ, et al. Developmental origins of health and disease: integrating environmental influences. Endocrinology. 2015;156(10):3416-21.

95. Sealey LA, Hughes BW, Sriskanda AN, Guest JR, Gibson AD, JohnsonWilliams $L$, et al. Environmental factors in the development of autism spectrum disorders. Environ Int. 2016;88:288-98.

96. Chun H, Leung C, Wen SW, McDonald J, Shin HH. Maternal exposure to air pollution and risk of autism in children: a systematic review and meta-analysis. Environ Pollut. 2020;256.

97. Dutheil F, Comptour A, Morlon R, Mermillod M, Pereira B, Baker JS, et al. Autism spectrum disorder and air pollution: a systematic review and meta-analysis. Environ Pollut. 2021;278.

98. Imbriani G, Panico A, Grassi T, Idolo A, Serio F, Bagordo F, et al. Early-life exposure to environmental air pollution and autism spectrum disorder: a review of available evidence. Int J Env Res Pub He. 2021;18(3).

99. Schaafsma SM, Pfaff DW. Etiologies underlying sex differences in autism spectrum disorders. Front Neuroendocrin. 2014;35(3):255-71.

100. Bilbo SD, Block CL, Bolton JL, Hanamsagar R, Tran PK. Beyond infection - Maternal immune activation by environmental factors, microglial development, and relevance for autism spectrum disorders. Exp Neurol. 2018;299:241-51

101. Church JS, Tijerina PB, Emerson FJ, Coburn MA, Blum JL, Zelikoff JT, et al. Perinatal exposure to concentrated ambient particulates results in autism-like behavioral deficits in adult mice. Neurotoxicology. 2018;65:231-40. 
102. Chang YC, Cole TB, Costa LG. Prenatal and early-life diesel exhaust exposure causes autism-like behavioral changes in mice. Part Fibre Toxicol. 2018;15.

103. Thirtamara Rajamani K, Doherty-Lyons S, Bolden C, Willis D, Hoffman C, Zelikoff J, et al. Prenatal and early-life exposure to high-level diesel exhaust particles leads to increased locomotor activity and repetitive behaviors in mice. Autism Res. 2013;6(4):248-57.

104. Weitekamp CA, Kerr LB, Dishaw L, Nichols J, Lein M, Stewart MJ. A systematic review of the health effects associated with the inhalation of particle-filtered and whole diesel exhaust. Inhal Toxicol. 2020;32(1):1-13.

105. Berman JD, Burkhardt J, Bayham J, Carter E, Wilson A. Acute air pollution exposure and the risk of violent behavior in the United States. Epidemiology. 2019;30(6):799-806.

106. Burkhardt J, Bayham J, Wilson A, Berman JD, O'Dell K, Ford B, et al. The relationship between monthly air pollution and violent crime across the United States. J Environ Econ Policy. 2019;9(2):188-205.

107. Fan S-J, Heinrich J, Bloom MS, Zhao T-Y, Shi T-X, Feng W-R, et al. Ambient air pollution and depression: a systematic review with metaanalysis up to 2019. Sci Total Environ. 2020;701.

108. Braithwaite I, Zhang S, Kirkbride JB, Osborn DPJ, Hayes JF. Air pollution (particulate matter) exposure and associations with depression anxiety, bipolar, psychosis and suicide risk: a systematic review and meta-analysis. Environ Health Persp. 2019;127(12).

109. Petruzzi S, Fiore M, DellOmo G, Alleva E. Exposure to ozone inhibits isolation-induced aggressive behavior of adult CD-1 male mice. Aggressive Behav. 1995:21(5):387-96.

110. Fiore M, Petruzzi S, Dell'Omo G, Alleva E. Prenatal sulfur dioxide exposure induces changes in the behavior of adult male mice during agonistic encounters. Neurotoxicol Teratol. 1998;20(5):543-8.

111. Homady M, Hussein H, Jiries A, Mahasneh A, Al-Nasir F, Khleifat K. Survey of some heavy metals in sediments from vehicular service stations in Jordan and their effects on social aggression in prepubertal male mice. Environ Res. 2002;89(1):43-9.

112. Musi B, Dell'Omo G, Ricceri L, Santucci D, Laviola G, Bignami G, et al. Effects of acute and continuous ozone (O3) exposure on activity/ exploration and social behavior of CD-1 mice. Neurotoxicology. 1994;15(4):827-35.

113. MCFrederick QS, Fuentes JD, Roulston TA, Kathilankal JC, Lerdau M. Effects of air pollution on biogenic volatiles and ecological interactions. Oecologia. 2009;160(3):411-20.

114. Ezenwa VO, Gerardo NM, Inouye DW, Medina M, Xavier JB. Animal behavior and the microbiome. Science. 2012;338(6104):198-9.

115. Sgritta M, Dooling SW, Buffington SA, Momin EN, Francis MB, Britton $R A$, et al. Mechanisms underlying microbial-mediated changes in social behavior in mouse models of autism spectrum disorder. Neuron. 2019;101(2):246-59 e6.

116. Sampson Timothy R, Mazmanian SK. Control of brain development, function, and behavior by the microbiome. Cell Host Microbe. 2015;17(5):565-76.

117. Valles Y, Francino MP. Air pollution, early life microbiome, and development. Curr Environ Health Rep. 2018;5(4):512-21.

118. Mutlu EA, Comba IY, Cho T, Engen PA, Yazici C, Soberanes S, et al. Inhalational exposure to particulate matter air pollution alters the composition of the gut microbiome. Environ Pollut. 2018;240:817-30.

119. del Blanco B, Barco A. Impact of environmental conditions and chemicals on the neuronal epigenome. Curr Opin Chem Biol. 2018:45:157-65.

120. Nilsson EE, Sadler-Riggleman I, Skinner MK, Mansuy I. Environmentally induced epigenetic transgenerational inheritance of disease. Environ Epigenet. 2018;4(2).

121. Martini M, Corces VG, Rissman EF. Mini-review: epigenetic mechanisms that promote transgenerational actions of endocrine disrupting chemicals: applications to behavioral neuroendocrinology. Horm Behav. 2020;119.

122. Hollander JA, Cory-Slechta DA, Jacka FN, Szabo ST, Guilarte TR, Bilbo $\mathrm{SD}$, et al. Beyond the looking glass: recent advances in understanding the impact of environmental exposures on neuropsychiatric disease. Neuropsychopharmacology. 2020;45(7):1086-96.

123. Robinson KJ, Bosch OJ, Levkowitz G, Busch KE, Jarman AP, Ludwig M. Social creatures: model animal systems for studying the neuroendocrine mechanisms of social behaviour. J Neuroendocrinol. 2019;31(12):e12807.

124. Hofmann HA, Beery AK, Blumstein DT, Couzin ID, Earley RL, Hayes LD, et al. An evolutionary framework for studying mechanisms of social behavior. Trends Ecol Evol. 2014;29(10):581-9.

125. Peterson EK, Buchwalter DB, Kerby JL, LeFauve MK, Varian-Ramos CW, Swaddle JP. Integrative behavioral ecotoxicology: bringing together fields to establish new insight to behavioral ecology, toxicology, and conservation. Curr Zool. 2017;63(2):185-94.

126. Niedzwiecki MM, Walker DI, Vermeulen R, Chadeau-Hyam M, Jones DP, Miller GW. The exposome: molecules to populations. Annu Rev Pharmacol Toxicol. 2019;59(1):107-27.

127. Brown RE, Brain JD, Wang N. The avian respiratory system: a unique model for studies of respiratory toxicosis and for monitoring air quality. Environ Health Perspect. 1997;105(2):188-200.

128. North MA, Kinniburgh DW, Smits JEG. Enclosure design for flock-level, chronic exposure of birds to air contaminant mixtures. Toxicol Mech Method. 2018;28(4):293-301.

129. Young RL, Ferkin MH, Ockendon-Powell NF, Orr VN, Phelps SM, Pogány Á, et al. Conserved transcriptomic profiles underpin monogamy across vertebrates. Proc Natl Acad Sci. 2019;116(4):1331-6.

130. Coleman MJ, DeLeon S, Webster MS, DeVoogd TJ, Dhondt AA. Developmental polychlorinated biphenyl exposure influences adult zebra finch reproductive behaviour. Plos One. 2020;15(3).

131. Stevens JS, Padilla S, DeMarini DM, Hunter DL, Martin WK, Thompson LC, et al. Zebrafish locomotor responses reveal irritant effects of fine particulate matter extracts and a role for TRPA1. Toxicol Sci. 2018;161(2):290-9.

132. Donaldson K, Tucker C, Taylor H, Chico T, McLeish J, Brown S. Skin exposure to micro- and nano-particles can cause haemostasis in zebrafish larvae. Thromb Haemost. 2017;103(04):797-807.

133. Kalueff AV, Stewart AM, Gerlai R. Zebrafish as an emerging model for studying complex brain disorders. Trends Pharmacol Sci. 2014;35(2):63-75

134. Lee S, Chun HS, Lee J, Park HJ, Kim KT, Kim CH, et al. Plausibility of the zebrafish embryos/larvae as an alternative animal model for autism: a comparison study of transcriptome changes. Plos One. 2018;13(9).

135. Cassar S, Adatto I, Freeman JL, Gamse JT, Iturria I, Lawrence C, et al. Use of zebrafish in drug discovery toxicology. Chem Res Toxicol. 2019;33(1):95-118.

136. Oliveira RF, Simões JM, Teles MC, Oliveira CR, Becker JD, Lopes JS. Assessment of fight outcome is needed to activate socially driven transcriptional changes in the zebrafish brain. Proc Natl Acad Sci. 2016;113(5):E654-61.

137. Nunes AR, Carreira L, Anbalagan S, Blechman J, Levkowitz G, Oliveira RF. Perceptual mechanisms of social affiliation in zebrafish. Scientific Rep. 2020;10(1).

138. Geng Y, Peterson RT. The zebrafish subcortical social brain as a model for studying social behavior disorders. Dis Models Mechanisms. 2019;12(8).

139. Green J, Collins C, Kyzar EJ, Pham M, Roth A, Gaikwad S, et al. Automated high-throughput neurophenotyping of zebrafish social behavior. J Neurosci Methods. 2012;210(2):266-71.

140. Dehmelt FA, von Daranyi A, Leyden C, Arrenberg AB. Evoking and tracking zebrafish eye movement in multiple larvae with ZebEyeTrack. Nat Protoc. 2018;13(7):1539-68.

141. Li X, Guo J-Y, Li X, Zhou H-J, Zhang S-H, Liu X-D, et al. Behavioural effect of low-dose BPA on male zebrafish: Tuning of male mating competition and female mating preference during courtship process. Chemosphere. 2017;169:40-52.

142. Weber DN, Hoffmann RG, Hoke ES, Tanguay RL. Bisphenol A exposure during early development induces sex-specific changes in adult zebrafish social interactions. J Toxicol Environ Health A. 2014:78(1):50-66.

143. Theodoridi A, Tsalafouta A, Pavlidis M. Acute exposure to fluoxetine alters aggressive behavior of zebrafish and expression of genes involved in serotonergic system regulation. Front Neurosci. 2017;11.

144. Ryan MJ. Female mate choice in a neotropical frog. Science. 1980;209(4455):523-5. 
145. Lynch KS, Crews D, Ryan MJ, Wilczynski W. Hormonal state influences aspects of female mate choice in the Túngara Frog (Physalaemus pustulosus). Horm Behav. 2006;49(4):450-7.

146. Kabelik D, Hofmann HA. Comparative neuroendocrinology: a call for more study of reptiles! Horm Behav. 2018;106:189-92.

147. Kabelik D, Weitekamp CA, Choudhury SC, Hartline JT, Smith AN, Hofmann HA. Neural activity in the social decision-making network of the brown anole during reproductive and agonistic encounters. Horm Behav. 2018;106:178-88.

148. Campos SM, Rojas V, Wilczynski W. Arginine vasotocin impacts chemosensory behavior during social interactions of Anolis carolinensis lizards. Horm Behav. 2020;124.

149. Wilczynski W, Quispe M, Muñoz MI, Penna M. Arginine vasotocin, the social neuropeptide of amphibians and reptiles. Front Endocrinol. 2017;8.

150. Fischer EK, O'Connell LA. Hormonal and neural correlates of care in active versus observing poison frog parents. Horm Behav. 2020;120.

151. Menzel R. The honeybee as a model for understanding the basis of cognition. Nat Rev Neurosci. 2012;13(11):758-68.

152. Toth AL, Robinson GE. Evo-devo and the evolution of social behavior. Trends Genet. 2007;23(7):334-41.

153. Rittschof CC, Bukhari SA, Sloofman LG, Troy JM, Caetano-Anolles D, Cash-Ahmed A, et al. Neuromolecular responses to social challenge: common mechanisms across mouse, stickleback fish, and honey bee. Proc Natl Acad Sci U S A. 2014;111(50):17929-34.

154. Shpigler HY, Saul MC, Corona F, Block L, Cash Ahmed A, Zhao SD, et al. Deep evolutionary conservation of autism-related genes. Proc Natl Acad Sci. 2017;114(36):9653-8.

155. Leonard RJ, Pettit TJ, Irga P, McArthur C, Hochuli DF. Acute exposure to urban air pollution impairs olfactory learning and memory in honeybees. Ecotoxicology. 2019.

156. Thimmegowda GG, Mullen S, Sottilare K, Sharma A, Mohanta SS, Brockmann $A$, et al. A field-based quantitative analysis of sublethal effects of air pollution on pollinators. Proc Natl Acad Sci. 2020;117(34):20653-61.

157. Gernat T, Rao VD, Middendorf M, Dankowicz H, Goldenfeld N, Robinson GE. Automated monitoring of behavior reveals bursty interaction patterns and rapid spreading dynamics in honeybee social networks. Proc Natl Acad Sci. 2018;115(7):1433-8.

158. Klinger EG, Camp AA, Strange JP, Cox-Foster D, Lehmann DM, PittsSinger T. Bombus (Hymenoptera: Apidae) Microcolonies as a tool for biological understanding and pesticide risk assessment. Environ Entomol. 2019:48(6):1249-59.

159. Arthur BJ, Sunayama-Morita T, Coen P, Murthy M, Stern DL. Multi-channel acoustic recording and automated analysis of Drosophila courtship songs. BMC Biology. 2013;11(1).
160. Williamson WR, Peek MY, Breads P, Coop B, Card GM. Tools for rapid high-resolution behavioral phenotyping of automatically isolated drosophila. Cell Rep. 2018;25(6):1636-49.e5.

161. Eom HJ, Liu YD, Kwak GS, Heo M, Song KS, Chung YD, et al. Inhalation toxicity of indoor air pollutants in Drosophila melanogaster using integrated transcriptomics and computational behavior analyses. Sci Rep-Uk. 2017;7.

162. Sobin C, Golub M. Behavioral outcome as a primary organizing principle for mechanistic data in developmental neurotoxicity. In: Handbook of developmental neurotoxicology. 2018. p. 337-47.

163. Carlson LM, Champagne FA, Cory-Slechta DA, Dishaw L, Faustman E, Mundy W, et al. Potential frameworks to support evaluation of mechanistic data for developmental neurotoxicity outcomes: a symposium report. Neurotoxicol Teratol. 2020;78.

164. Blumstein DT. Towards an integrative understanding of social behavior: new models and new opportunities. Front Behavioral Neurosci. 2010.

165. Weitekamp CA, Hofmann HA. Evolutionary themes in the neurobiology of social cognition. Curr Opin Neurobiol. 2014;28:22-7.

166. Yartsev MM. The emperor's new wardrobe: rebalancing diversity of animal models in neuroscience research. Science. 2017:358(6362):466-9.

167. Brenowitz EA, Zakon HH. Emerging from the bottleneck: benefits of the comparative approach to modern neuroscience. Trends Neurosci. 2015;38(5):273-8

168. Ankley GT, Bennett RS, Erickson RJ, Hoff DJ, Hornung MW, Johnson RD, et al. Adverse outcome pathways: a conceptual framework to support ecotoxicology research and risk assessment. Environ Toxicol Chem. 2010;29(3):730-41.

169. Bal-Price A, Lein PJ, Keil KP, Sethi S, Shafer T, Barenys M, et al. Developing and applying the adverse outcome pathway concept for understanding and predicting neurotoxicity. Neurotoxicology. 2017;59:240-55.

170. Liang Y, Rudik I, Zou EY, Johnston A, Rodewald AD, Kling CL. Conservation cobenefits from air pollution regulation: evidence from birds. Proc Natl Acad Sci. 2020;117(49):30900-6.

171. Tost H, Champagne FA, Meyer-Lindenberg A. Environmental influence in the brain, human welfare and mental health. Nat Neurosci. 2015;18(10):1421-31.

172. Payne-Sturges D, Scammell M, Levy J, Cory-Slechta D, Symanski E, Carr Shmool J, et al. Methods for evaluating the combined effects of chemical and nonchemical exposures for cumulative environmental health risk assessment. Int J Env Res Pub He. 2018;15(12).

\section{Publisher's Note}

Springer Nature remains neutral with regard to jurisdictional claims in published maps and institutional affiliations.
Ready to submit your research? Choose BMC and benefit from:

- fast, convenient online submission

- thorough peer review by experienced researchers in your field

- rapid publication on acceptance

- support for research data, including large and complex data types

- gold Open Access which fosters wider collaboration and increased citations

- maximum visibility for your research: over $100 \mathrm{M}$ website views per year

At $\mathrm{BMC}$, research is always in progress.

Learn more biomedcentral.com/submissions 